Serban: None declared, Gerolamo Bianchi: None declared, Luca Cantarini: None declared, Francesco Ciccia Grant/research support from: CELGENE, PFIZER, Consultant for: UCB, NOVARTIS, CELGENE, PFIZER, LILLY, Paid instructor for: UCB, NOVARTIS, CELGENE, PFIZER, LILLY, JANSSEN, Speakers bureau: UCB, NOVARTIS, CELGENE, PFIZER, LILLY, JANSSEN, MSD, ROCHE, AMGEN, Lorenzo Dagna Consultant for: Prof Lorenzo Dagna received consultation honoraria from Abbvie, Amgen, Biogen, Bristol-Myers Squibb, Celltrion, Novartis, Pfizer, Sanofi-Genzyme, and SOBI., Marcello Govoni: None declared, Carlomaurizio Montecucco: None declared, Roberta Priori: None declared, Angelo Ravelli Grant/research support from: Angelini, AbbVie, Bristol-Myers Squibb, Johnson \& Johnson, Novartis, Pfizer, Reckitt Benkiser, and Roche, Consultant for: Angelini, AbbVie, Bristol-Myers Squibb, Johnson \& Johnson, Novartis, Pfizer, Reckitt Benkiser, and Roche, Speakers bureau: Angelini, AbbVie, Bristol-Myers Squibb, Johnson \& Johnson, Novartis, Pfizer, Reckitt Benkiser, and Roche, Paolo Sfriso: None declared, Luigi Sinigaglia Speakers bureau: Yes, I,ve been invited speaker by Amgen, Ely Lilly, UCB, Abbvie, Roche and BMS.

DOI: 10.1136/annrheumdis-2019-eular.4535

\section{THU0570 EFFICACY AND SAFETY OF ANAKINRA IN THE TREATMENT OF AUTOIMMUNE MYOCARDITIS}

Giacomo De Luca, Corrado Campochiaro, Giulio Cavalli, Silvia Sartorelli, Lorenzo Dagna, Myocarditis Clinic - Cardiovascular Immunopathology Unit at UnIRAR. IRCCS San Raffaele Hospital and Scientific Institute, Unit of Immunology, Rheumatology, Allergy and Rare Diseases, Milan, Italy

Background: Virus-negative or "autoimmune" myocarditis(VNM) is a severe, inflammatory heart disease with a poor prognosis, and is a leading cause of inflammatory dilated cardiomyopathy(i-DCM). Therapies are limited. Preliminary data indicate that interleukin-1(IL-1) plays a key role in the initiation and maintainance of the inflammatory heart response, sustaining an auto-inflammatory cycle ${ }^{[1,2]}$.

Objectives: to evaluate the efficacy and safety of anakinra(ANK) in improving Left Ventricular Ejection Fraction(LVEF) on transthoracic echocardiography(TTE) in patients with VNM.

Methods: Biopsy-proven VNM patients were enrolled and treated with ANK $100 \mathrm{mg}$ daily subcutaneously. All patients received treatment with the maximum tolerated dose of any beta blockers and ACE-inhibitors, according to current guidelines. At baseline and $8 \pm 4$ weeks after ANK therapy, all patients underwent a full evaluation with assessment of functional status(New York Heart Association[NYHA]), measurement of highsensitive troponin $\mathrm{T}(\mathrm{hs}-\mathrm{TnT})$ and NT-proBNP serum levels, electrocardiography(ECG), 24h-ECG-Holter, TTE and cardiac magnetic resonance(CMR). Any myocarditis-related complication, cardiovascular deaths and adverse events(AEs) was recorded during follow-up. Continuous variables were assessed with the Wilcoxon signed-rank test for non-parametric tests and a $p$ value $<0.05$ was considered statistically significant.

Results: Eleven patients( $F / M=5 / 6$, mean age $46,2 \pm 12,2$ years) diagnosed with EBM-proven VNM were enrolled. Nine patients received ANK as first line therapy, and in 5 cases ANK was used as monotherapy; ANK was combined with prednisone(mean dose $31,7 \pm 16,7 \mathrm{mg}$ daily) in 6 patients, 5 of them were concomitantly treated with azathioprine. On EMB, 6 patients were classified as i-DCM, 3 with acute VNM e 1 with active and chronic $\mathrm{VNM}^{[3-4]}$. Clinical onset was characterized by congestive heart failure in the most cases(72.7\%). The majority of patients $(72.7 \%)$ was in NYHA class III-IV. Mean LV-EF on TTE at baseline was $38,7 \%$ $\pm 19,6$, with comparable findings on $\operatorname{CMR}(36,45 \% \pm 18,0)$, and 8 patients $(72.7 \%)$ had a depressed LV-EF $(<55 \%)$. At baseline, mean levels of hsTnT and NT-proBNP were 150,0 $\pm 153,9 \mathrm{ng} / \mathrm{L}$ and $6968,8 \pm 10788,4 \mathrm{pg} / \mathrm{ml}$, respectively. Hs-TnT and NT-proBNP levels were elevated in 10(90.9\%) and 9 patients $(81.8 \%)$ respectively. At 8 weeks, LV-EF improved in 10 patients $(90.9 \%)$. The LV-EF increase was $>10 \%$ in 5 patients $(45.5 \%)$ and between $5-10 \%$ in 5 cases $(45.5 \%)$; only 1 patient showed a $<10 \%$ LVEF decrease. Mean LV-EF at the end of follow-up improved to $49,4 \%$ $\pm 10,8(p=0.059)$. When evaluating the 8 patients with baseline reduced LV-EF, the LV-EF improvement was statistically significant (baseline $29,2 \% \pm 12,9$; after ANK 45.2\% $\pm 9.2, p=0.025)$. The LV-EF amelioration was paralleled by clinical improvements in all patients, since the majority of them $(90.9 \%)$ were in NYHA class I-II at the end of follow-up. Consistently, hs-TnT declined after 8 weeks $(64,6 \pm 100,7 \mathrm{ng} / \mathrm{L}, \mathrm{p}=0,028)$, and a similar trend was observed for NT-proBNP, even though not statistical significant $(2582,6 \pm 5048,1 \mathrm{pg} / \mathrm{ml}, \mathrm{p}=0,06)$. We did not observe any myocarditis-related death or complications, nor any ANK-related AEs.

Conclusion: Our pilot study supports the efficacy and safety of ANK in the treatment of inflammatory heart failure in VNM and provides the first clinical evidence to support the therapeutic blockade of $\mathrm{IL}-1$ in myocarditis.

\section{REFERENCES:}

[1] De LucaG,et al.Ann Intern Med.2018;169:819-820.

[2] De LucaG,et al. Front Immunol.2018;9:1335.

[3] RichardsonP,et al. Circulation.1996;93:841-2.

[4] AretzHT,et al. Am J Cardiovasc Pathol.1987;1:3-14.

Acknowledgement: Dr Giovanni Peretto and Dr Simone Sala from Unit of Arrhythmology and Cardiac Electrophysiology

Disclosure of Interests: Giacomo De Luca Consultant for: Dr Giacomo De Luca received consultation honoraria from Pfizer and SOBI., Corrado Campochiaro Consultant for: Dr Corrado Campochiaro received consultation honoraria from Pfizer., Giulio Cavalli Consultant for: Dr Giulio Cavalli received consultation honoraria from Pfizer, Novartis and SOBI., Silvia Sartorelli: None declared, Lorenzo Dagna Consultant for: Prof Lorenzo Dagna received consultation honoraria from Abbvie, Amgen, Biogen, Bris tol-Myers Squibb, Celltrion, Novartis, Pfizer, Sanofi-Genzyme, and SOBI. DOI: 10.1136/annrheumdis-2019-eular.3067

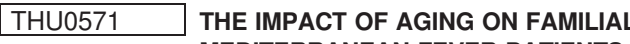 MEDITERRANEAN FEVER PATIENTS}

Okan Aydin, Serdal Ugurlu, Bugra Han Egeli, Asli Ece Soykut, Deniz Demir, Huri Ozdogan. University of Istanbul- Cerrahpasa, Istanbul, Turkey

Background: Familial Mediterranean Fever (FMF) is a monogenic autoinflammatory disorder with innate immune activation with an onset before age 20 in approximately $90 \%$ of the patients. There is scarce data on the effect of aging on FMF patients over 40 years of age

Objectives: This study aims to collect data on FMF patients who have survived over 40 years of age. Here we report our preliminary data on disease course and treatment status and comorbidities of our patients with FMF.

Methods: Among the FMF patients who have been followed in our FMF outpatient clinic with a pool of approximately 5000 patients, those who have aged 40 and over are being included to the study. As by today 180 patients are considered for evaluation. The files of patients were reviewed and a standard questionnaire was used to interview the patients. Here we report the results of 100 of these patients $(56 \%)$ who were contacted for this purpose. These patients were questioned on their demographic characteristics, comorbid conditions, colchicine treatment details, and attack information. In order to see the trend of the change in the parameters assessed, the patients were divided into two groups based on their present age (Group 1: $40-50$ years, Group 2: $\geq 50$ years). Results: A total of 100 (78 F, 22M) patients were evaluated. There were $61(46 \mathrm{~F}, 15 \mathrm{M})$ patients aged between $40-50$ years and $39(32 \mathrm{~F}, 7 \mathrm{M})$ over 50. The demographic characteristics and clinical features of these patients are given in Table 1. Besides 3 , all patients were still on colchicine reg ularly. Ninety-six percent of the patients declared overall benefit from colchicine therapy; however $38 \%$ experienced a side effect related to this treatment. Over $88 \%$ of the patients reported decrease in severity and frequency of FMF attacks. The mean daily colchicine dose was lower in the age 50 and over group $(1.7 \pm 0,77 \mathrm{mg}$ versus $1,35 \pm 0,38 \mathrm{mg})$. There were no patients with AA amyloidosis in neither age group. The mean duration from the last attack increased from $15.3 \pm 19.7$ months to $35.6 \pm$ 52 months in the older patients. One or more additional disease was present in $75 \%$ of this patient group. Among the comorbidities hyperten sion was the most frequent, diagnosed in $25 \%$ of the patients, followed by hypothyroidism (16\%), diabetes mellitus $(10 \%)$ and cardiac disease $(5 \%)$. Sixty-five of the patients were receiving other medications in addition to colchicine.

Table 1. Clinical course and co-morbidities in two age groups over 40 years

\begin{tabular}{|c|c|c|c|}
\hline $\mathrm{n}$ & $\begin{array}{l}\text { Group 1* } \\
(n=61)\end{array}$ & $\begin{array}{c}{\text { Group } 2^{* *}}_{(n=39)}\end{array}$ & $p$ \\
\hline Sex (F:M); current age (mean $\pm S D)(y r)$ & $\begin{array}{c}(46: 15) ; 45.5 \pm \\
2.29\end{array}$ & $\begin{array}{c}(32: 7) ; 57.05 \pm \\
6.81\end{array}$ & $\begin{array}{c}0,43 \\
<0.001\end{array}$ \\
\hline $\begin{array}{l}\text { Mean duration since the last episode, } \\
\text { (mean } \pm S D, \text { mo) }\end{array}$ & $\begin{array}{c}15.3 \pm 19.7(1- \\
60)\end{array}$ & $\begin{array}{l}35.67 \pm 52.05 \\
\quad(1-276)\end{array}$ & 0,012 \\
\hline $\begin{array}{l}\text { Number of patients on colchicine therapy, } n \\
(\%)\end{array}$ & $59(96.7)$ & $38(97.4)$ & NS \\
\hline Mean colchicine dose, mg/day (current) & $1.7 \pm 0.76$ & $1.41 \pm 0.45$ & 0.03 \\
\hline $\begin{array}{l}\text { Number of patients with decrease in attack } \\
\text { severity, } \mathrm{n}(\%)\end{array}$ & $54(88,5)$ & $35(89,7)$ & NS \\
\hline Number of patients with decrease in attack & $57(93,4)$ & $37(94,8)$ & NS \\
\hline
\end{tabular}

frequency,

$57(93,4)$

$37(94,8)$

NS 